\title{
REFIS DA CRISE (E REFIS DA COPA) E A ATUAL SISTEMÁTICA DA SUSPENSÃO DA PRETENSÃO PUNITIVA DO ESTADO PELO PARCELAMENTO, NOS CRIMES TRIBUTÁRIOS
}

\section{CRISIS' REFIS (AND WORLD CUP'S REFIS) AND THE CURRENT FRAMEWORK OF THE SUSPENSION OF STATE'S PUNITIVE POWER BY INSTALLMENT IN TAX CRIMES}

Cícero Marcos Lima Lana ${ }^{1}$

Resumo: O presente trabalho tratará dos efeitos que o parcelamento do débito tributário traz à esfera penal. A análise tem como razão principal a reabertura do prazo para formalização do parcelamento do Refis da Crise, criado originalmente pela Lei no 11.941/09, bem como a edição da Lei $n^{\circ}$ 11382/11, que trouxe, quando de sua edição, novos dispositivos atinentes ao tema do parcelamento. Buscar-se-á verificar como a questão deve ser tratada, especificamente como conjugar os diversos dispositivos legais existentes.

Palavras-chave: parcelamento, punibilidade, crime, tributário

\begin{abstract}
This paper will discuss the effects that the tax debt installment brings to the criminal sphere. The main reason the analysis has is the reopen of the period for formalization of 'Refis da Crise', originally created by Law No. 11.941/09, as well as the edition of Law No. 11382/11, which brought at the time of it promulgation, new devices at the theme of the installment. Search it will verify how the issue should be dealt specifically how to combine the various existing legal provisions.
\end{abstract}

KeyWords: subdivision, punishment, crime, tax

\section{INTRODUÇÃO}

\footnotetext{
${ }^{1}$ Advogado; Especialista em Direito Tributário pelo IBET/SP; Especialista em Direito Penal pela Escola Superior do Ministério Público de São Paulo; Mestre em Direito Penal pela PUC/SP; Doutorando em Direito Penal pela PUC/SP. Email: cicero@lanaadvogados.adv.br
} 
A suspensão da punibilidade nos crimes tributários, em razão da celebração do parcelamento do débito, sempre gerou inúmeras discussões doutrinárias e, sobretudo, jurisprudenciais. Tais discussões são fomentadas e, de certo modo, reacendidas a cada edição legislativa sobre o tema.

No entanto, tais discussões se encontravam significativamente reduzidas, desde a edição da Lei no 10.684/03, mormente em razão da tomada de posição do Supremo Tribunal Federal.

Entendeu a Corte Constitucional, ao analisar aquela legislação, que o pagamento do crédito tributário extingue a punibilidade, e o parcelamento deste, suspende a pretensão punitiva do Estado. E, não há relevância alguma a data do pagamento ou da celebração do parcelamento."2

$\mathrm{Na}$ esteira desse entendimento, a Lei $\mathrm{n}^{\mathrm{o}} 11941 / 09$ que criou nova modalidade de parcelamento de débitos tributários, disciplinou em seu artigo 68 que a pretensão punitiva do Estado ficaria suspensa com a inclusão no parcelamento dos débitos que ensejaram ações penais, sem fazer qualquer menção/limitação sobre a data da celebração e o momento processual.

A Lei $\mathrm{n}^{\circ} 12.382$, promulgada em 25 de fevereiro de 2011, alterou o artigo 83 da Lei $\mathrm{n}^{\circ}$ 9430/96, modificando o entendimento sobre a consequiência que a celebração do parcelamento do débito tributário traz ao processo penal, mormente em relação ao momento em que este parcelamento deve ser celebrado para provocar efeitos penais.

No final do ano de 2013 (outubro), foi editada a Lei $\mathrm{n}^{\circ} 12.865$ reabrindo prazo para formalização de adesão ao programa de parcelamento que havia sido criado pela Lei $n^{\circ}$ 11.941/09 e cujo prazo havia se encerrado, originalmente, no ano de 2009.

Esta reabertura foi novamente disciplinada pela Lei ${ }^{\circ} 12.973 / 14$ e, por fim, pela Lei ${ }^{\circ}$ 12.996/14 (Refis da Copa).

A proposta deste trabalho é analisar qual a conseqüência penal que o parcelamento celebrado em razão da reabertura do prazo para adesão ao Refis da crise traz ao processo penal; especificamente, tratar de qual será a regra aplicável: a limitação trazida pela Lei no 12.382/11,

${ }^{2}$ LANA, Cícero Marcos Lima. Lei 12.382 alterou extinção e suspensão de punibilidade. Disponível em http://www.conjur.com.br/2013-jan-25/cicero-lana-lei-12382-alterou-extincao-punibilidade-crime-

tributario\#author. Acesso em 11/07/2014 
ou a extensão trazida pela Lei $n^{\circ} 11941 / 09$ (e suas posteriores reaberturas de prazo - Leis $n^{\circ}$ $12.865 / 13,12.973 / 14$ e 12.996/14).

\section{DISPOSIÇÕES LEGAIS}

A lei no 9249 de 26 de dezembro de 1995 trouxe a lume a possibilidade de extinção da punibilidade do agente, nos crimes tributários, caso o pagamento do tributo ou contribuição social fosse feito antes do recebimento da denúncia; outrossim, nada dispôs a legislação sobre parcelamento do débito e suas implicações na apuração dos crimes de sonegação físcal.

Somente em 10 de abril de 2000, quando foi publicada a lei no 9964 que instituiu o Programa de Recuperação Fiscal - REFIS, foi o parcelamento do débito expressamente tratado.

Dispôs referida lei que a suspensão da punibilidade ocorreria durante o período em que a empresa fosse optante pelo Programa, desde que formalizasse o parcelamento antes do recebimento da denúncia.

Vale destacar, desde logo, que a suspensão da pretensão punitiva do Estado apenas iria ocorrer, nos termos da legislação mencionada, em relação aos débitos que foram inseridos no Programa de Recuperação Fiscal, ficando excluídos, portanto, todos os débitos não abrangidos pelo REFIS.

Posteriormente, no dia 30 de maio de 2003, foi editada Lei Federal n ${ }^{\circ} 10.684$, que dispôs sobre parcelamento especial de débitos junto à Procuradoria da Fazenda Nacional, Secretaria da Receita Federal e Instituto Nacional do Seguro Social; esta legislação tratou em seu artigo $9^{\circ}$ e parágrafos, sobre as implicações que a adesão ao parcelamento especial traria na esfera penal, dispondo estar suspensa a pretensão punitiva do Estado enquanto estiver a pessoa jurídica incluída no regime de parcelamento. 
"Portanto, assim como acontecia com o Refis, durante o tempo em que a pessoa optante pelo parcelamento estivesse nele incluída, não poderia sofrer qualquer punição, ou mesmo qualquer persecução penal, por estar suspensa a pretensão punitiva do Estado. ”3

Diferentemente do que ocorria no Programa de Recuperação Fiscal, onde a suspensão da punibilidade apenas se operava caso a opção pelo Programa tivesse sido feita antes do recebimento da denúncia, no Parcelamento Especial, este marco temporal foi ignorado, não dispondo a lei sobre qualquer restrição no que diz respeito ao momento da adesão ao parcelamento.

Com isso, desde que formalizado o parcelamento, independente do momento processual, deveria ser suspensa a pretensão punitiva do Estado.

ESTELLITA (2003), em artigo publicado logo após a edição da Lei 10684/03, ao tratar do tem concluiu:

“(...)

Quanto aos efeitos do pagamento, uma leitura apressada, feita sob a ótica da disciplina do antigo Refis, do novo $\$ 2^{\circ}$ do art. $9^{\circ}$ poderia levar à crença de se tratar de norma que faz referência ao momento final do parcelamento, ou seja, que o final do parcelamento, implicando em pagamento, levaria à extinção da punibilidade. Sim, o entendimento está correto, mas o dispositivo diz mais que isso. Em nosso entender, o dispositivo pode perfeitamente ser interpretado de forma a permitir que sempre que houver pagamento, independentemente de ser o momento final do parcelamento, extinta estará a punibilidade e, agora, sem limite temporal, isto é, sem que o recebimento da denúncia inviabilize o efeito jurídico-penal do pagamento integral do tributo.

Essa interpretação se assenta em dois fundamentos. Primeiro deles: na disciplina anterior (do Refis), o $\S 3^{\circ}$ expressamente atrelava a extinção da punibilidade ao pagamento das parcelas do parcelamento, verbis: Extingue-se a punibilidade dos crimes referidos neste artigo quando a pessoa jurídica relacionada com o agente efetuar o pagamento integral dos débitos oriundos de tributos e contribuições sociais, inclusive acessórios, que tiverem sido objeto de concessão de parcelamento antes do recebimento da denúncia criminal (grifamos). A nova disciplina é bem diferente sob este aspecto, confira-se: Extingue-se a punibilidade dos crimes referidos neste artigo quando a pessoa jurídica relacionada com o agente efetuar o pagamento integral dos débitos oriundos de tributos e contribuições sociais, inclusive acessórios (art. $9^{\circ}, \S 2^{\circ}$ ). $\mathrm{O}$ segundo deles reside na questão da igualdade: se o agente pode, a qualquer momento, parcelar o débito, suspendendo a punibilidade que, ao cabo do parcelamento, será extinta, com maior razão a mesma extinção deve atingir aquele que opta por, num só ato, pagar integralmente o débito.

Tal qual ocorre relativamente ao parcelamento, a nova disciplina dos efeitos jurídico-penais do pagamento, por ser mais benéfica, retroage atingindo todos os cidadãos que se encontrem nesta situação, não importando, igualmente, o estágio processual (art. $5^{\circ}, \mathrm{XL}, \mathrm{CF}$, art. $\left.2^{\circ}, \mathrm{CP}\right)$.

$(\ldots)^{m}$

${ }^{3}$ LANA, Cícero Marcos Lima. Lei 12.382 alterou extinção e suspensão de punibilidade. Disponível em http://www.conjur.com.br/2013-jan-25/cicero-lana-lei-12382-alterou-extincao-punibilidade-crimetributario\#author. Acesso em 11/07/2014 
Em maio de 2009, a Lei $\mathrm{n}^{\circ} 11.941$ concedeu nova oportunidade para o parcelamento dos débitos tributários, criando o chamado 'Refis da crise'.Em seu artigo 68 dispôs a legislação que:

“Art. 68. É suspensa a pretensão punitiva do Estado, referente aos crimes previstos nos arts. $1^{\circ}$ e $2^{\circ}$ da Lei no 8.137 , de 27 de dezembro de 1990, e nos arts. 168-A e 337-A do Decreto-Lei n ${ }^{\circ} 2.848$, de 7 de dezembro de 1940 - Código Penal, limitada a suspensão aos débitos que tiverem sido objeto de concessão de parcelamento, enquanto não forem rescindidos os parcelamentos de que tratam os arts. $1^{\circ}$ a $3^{\circ}$ desta Lei, observado o disposto no art. 69 desta Lei.

Parágrafo único. A prescrição criminal não corre durante o período de suspensão da pretensão punitiva".

Mantida estava, portanto, toda implicação que o parcelamento traria na esfera penal, de acordo com as legislações precedentes.

A Lei 12.382/11, no entanto, alterou o artigo 83 da Lei 9430/96, que passou a ter a seguinte redação:

“Art. 83. A representação fiscal para fins penais relativa aos crimes contra a ordem tributária previstos nos arts. $1^{\circ} \mathrm{e}$ $2^{\circ}$ da Lei $n^{\circ}$ 8.137, de 27 de dezembro de 1990, e aos crimes contra a Previdência Social, previstos nos arts. 168-A e 337-A do Decreto- Lei no 2.848, de 7 de dezembro de 1940 - Código Penal, será encaminhada ao Ministério Público depois de proferida a decisão final, na esfera administrativa, sobre a exigência fiscal do crédito tributário correspondente.

Parágrafo único. As disposições contidas no caput do art. 34 da Lei no 9.249, de 26 de dezembro de 1995, aplicamse aos processos administrativos e aos inquéritos e processos em curso, desde que não recebida a denúncia pelo juiz.

$\S 1^{\circ} \mathrm{Na}$ hipótese de concessão de parcelamento do crédito tributário, a representação fiscal para fins penais somente será encaminhada ao Ministério Público após a exclusão da pessoa física ou jurídica do parcelamento.

$\S 2^{\circ}$ É suspensa a pretensão punitiva do Estado referente aos crimes previstos no caput, durante o período em que a pessoa física ou a pessoa jurídica relacionada com o agente dos aludidos crimes estiver incluída no parcelamento, desde que o pedido de parcelamento tenha sido formalizado antes do recebimento da denúncia criminal.

$\S 3^{\circ}$ A prescrição criminal não corre durante o período de suspensão da pretensão punitiva.

$\S 4^{\circ}$ Extingue-se a punibilidade dos crimes referidos no caput quando a pessoa física ou a pessoa jurídica relacionada com o agente efetuar o pagamento integral dos débitos oriundos de tributos, inclusive acessórios, que tiverem sido objeto de concessão de parcelamento.

$\S 5^{\circ} \mathrm{O}$ disposto nos $\S \S 1^{\circ}$ a $4^{\circ}$ não se aplica nas hipóteses de vedação legal de parcelamento.

$\S 6^{\circ}$ As disposições contidas no caput do art. 34 da Lei $n^{\circ}$ 9.249, de 26 de dezembro de 1995, aplicam-se aos processos administrativos e aos inquéritos e processos em curso, desde que não recebida a denúncia pelo juiz."

O parcelamento do débito, a partir de fevereiro de 2011, somente traria como conseqüência a suspensão da pretensão punitiva, se celebrado antes do Juiz aceitar a exordial acusatória. Em 09 de outubro de 2013, a Lei $n^{\text {o }} 12.865$ reabriu o prazo para adesão ao parcelamento criado com o Refis da crise (Lei n $\left.{ }^{\circ} 11.941 / 09\right)$.

${ }^{4}$ ESTELLITA, Heloisa. Pagamento e parcelamento nos crimes tributários: a nova disciplina da lei $\mathbf{n}$. 10.684/03. Boletim IBCCRIM. São Paulo, v.11, n.130, p. 2-3, set. 2003. 
Esta extensão do prazo foi novamente tratada na Lei no $12.973 / 14$ e, finalmente, na Lei ${ }^{\circ}$ 12.996/14 (que criou o chamado Refis da Copa). Em todas as três legislações (Lei n ${ }^{\circ}$ 12.865/13, 12.973/14 e Lei n ${ }^{\circ} 12.996 / 14$ ) o prazo para adesão ao parcelamento foi reaberto, bem como todas as condições do mesmo. Mas, em nenhuma das legislações o parcelamento foi tratado de maneira específica como causa suspensiva da punibilidade dos crimes tributários.

Ao reabrirem o prazo para a adesão ao parcelamento, com todas as condições do parcelamento original (criado pela Lei $\mathrm{n}^{\circ}$ 1941/09), e sem disporem das conseqüências para o processo penal, referidas legislações acabam por colocar em dúvida se o comando existente sobre a suspensão volta a valer (ou seja, sem que haja momento processual especifico para que a adesão suspenda o curso do processo penal) ou se a edição da Lei $\mathrm{n}^{\circ} 12.382 / 11$ e seu veto temporal ainda estão válidos para os novos parcelamentos a serem celebrados (e, com isso, somente seriam suspensas as ações penais futuras, e não as que estão em andamento).

\section{SISTEMATIZAÇÃO DOS COMANDOS LEGAIS}

Mais uma vez, a questão que se coloca em face de todas as determinações legais elencadas, diz respeito à amplitude, ou melhor, à abrangência que a suspensão da punibilidade deve ter, especialmente se o parcelamento do Refis da crise (ou Refis da Copa) for celebrado e o contribuinte for réu em processo criminal por sonegação fiscal que já esteja em curso (denuncia já recebida), oriundo de débito tributário objeto do parcelamento.

A Lei $\mathrm{n}^{\circ} 10.684 / 03$ que criou o Parcelamento Especial, não determinou qual parcelamento tem o condão de suspender a pretensão punitiva do Estado, jamais restringindo seu âmbito de aplicação; pelo contrário, foi abrangente ao extremo, ao deixar de limitar esta aplicação.

E, a Lei $n^{\circ} 11.941 / 09$ (refis da crise) seguiu esta mesma linha de raciocínio, deixando de impor qualquer restrição à suspensão do processo penal, desde que formalizado o parcelamento do débito tributário.

A intenção das normas, salvo melhor juízo, era apenas e tão somente forçar os inadimplentes a parcelarem os débitos, premiando-os com a suspensão da punibilidade. 
Com a edição da Lei 12.382/11 se buscou uma restrição à adoção do benefício penal, sendo o mesmo concedido apenas ao parcelamento celebrado antes do recebimento da denúncia.

A diferença entre os diplomas legislativos está na questão do momento em que se deve promover o parcelamento para que a suspensão da punibilidade ocorra.

Se antes este parcelamento poderia ser feito a qualquer tempo (antes da denúncia, depois da denúncia, depois da sentença e até mesmo em eventual cumprimento de pena), após 28 de fevereiro de 2011, com a Lei $n^{\circ} 12.382 / 11$, somente poderá haver a suspensão da punibilidade se o parcelamento for celebrado antes do recebimento da denúncia.

Mas, e agora, como tratar o processo penal por crime de sonegação fiscal se o prazo para adesão ao parcelamento criado em 2009 foi reaberto e as legislações que permitiram esta adesão não trataram especificamente do tema suspensão da punibilidade?

Estaria o contribuinte que aderir ao parcelamento nos dias atuais em situação diferente (e menos vantajosa) em relação àquele que o fez em 2009 ?

\section{CONCLUSÕES}

A análise dos textos legais discutidos leva, forçosamente, a algumas conclusões.

Em primeiro lugar, como já disposto anteriormente, até o início do ano de 2011, qualquer forma ou modalidade de parcelamento suspendia a pretensão punitiva do Estado, ainda que já tenha iniciado o processo criminal.

No entanto, após 28 de fevereiro de 2011, somente a celebração do parcelamento efetuada antes do recebimento da denúncia, é que teria o condão de suspender a pretensão punitiva do Estado.

As Leis no 12.865/13, 12.973/14 e Lei n 12.996/14, que reabriram o prazo para adesão ao Refis da crise (ou Refis da Copa), permitiram ao contribuinte ingressar no parcelamento com pequenas alterações na sistemática de cálculo das parcelas, prazo e forma de pagamento, e utilização de prejuízos fiscais; mantidas todas demais condições, ai incluída a suspensão da pretensão punitiva do Estado. 
Todo contribuinte que se vê processado criminalmente por sonegação fiscal e que tenha interesse na celebração do parcelamento do débito, enxerga nesse a possibilidade de adimplir suas obrigações e, evidentemente, e até mais importante, ficar livre da persecução penal.

Não faz sentido algum que o prazo para adesão ao parcelamento seja reaberto, permitindo que mais contribuintes possam ingressar na sistemática de pagamento a longo prazo, e seja mantida a limitação trazida pela Lei $n^{\circ} 12.382 / 12$, no que tange ao momento de celebração deste parcelamento para produzir efeitos penais.

Se a todos é concedido o benefício de parcelar o débito em condições mais favoráveis do que normalmente se admite, nos parece evidente que estas melhores condições devem ter lugar, também, na persecução penal, mais especificamente, na conseqüência que este parcelamento trará ao processo penal.

Por tudo isso, entendemos que os contribuintes que fizerem a adesão ao parcelamento, nos moldes como tratado pelas Leis $\mathrm{n}^{\circ}$ 12.865/13, 12.973/14 e 12.996/14, devem ter suspensas a pretensão punitiva do Estado, em relação aos crimes de sonegação fiscal oriundos dos débitos parcelados, independente do momento em que se encontram os processos penais, devendo se desconsiderada, para estes casos específicos, a limitação temporal trazida pela Lei n ${ }^{\circ}$ 12.382/12.

\section{REFERÊNCIAS}

ANDRADE FILHO, Edmar Oliveira. Direito Penal Tributário. 2a Ed, São Paulo: Atlas, 1997.

BALTAZAR JUNIOR, José Paulo. O crime de omissão no recolhimento de contribuições sociais arrecadadas. Porto Alegre: Livraria do Advogado, 2000

CARVAlHO, Aurora Tomazini. Direito Penal Tributário. São Paulo: Quartier Latin, 2009.

CASTRO, Wellington Claudio Pinho. Apropriação Indébita Previdenciária, in Revista da Associação dos Juízes Federais do Brasil, ano 19, nº 63, 2000 
EISELE, Andreas. Apropriação Indébita e Ilicito Penal Tributario. São Paulo: Dialética, 2001.

LANA, Cícero Marcos Lima. Os crimes de sonegação fiscal e o princípio da intervenção mínima. $2^{\mathrm{a}}$ ed. Campinas: Impactus, 2007

. Crime de apropriação indébita previdenciária. Curitiba: Juruá, 2013. 